\title{
Genius Loci Kampung Areng di Lembang
}

\section{Studi Kasus: Wisata Astronomi Imah Noong di Desa Wangunsari Kampung Eduwisata Areng Lembang Kabupaten Bandung Barat}

\author{
Tyas Santri \\ Fakultas Teknik, Program Studi Arsitektur \\ Universitas Langlangbuana \\ Jl. Karapitan 116, Bandung \\ tyassantriarch@gmail.com
}

Agus S Ekomadyo

Sekolah Arsitektur Perencanaan dan Pengembangan

Kebijakan, Program Studi Arsitektur

Institut Teknologi Bandung

Jl. Tamansari 64, Bandung

aekomadyo00@gmail.com

\author{
Rakhmat Fitranto Aditra \\ Sekolah Arsitektur Perencanaan dan Pengembangan \\ Kebijakan, Program Studi Arsitektur \\ Institut Teknologi Bandung \\ Jl. Tamansari 64, Bandung \\ Rakhmat.aditra@gmail.com
}

\begin{abstract}
Abstrak - Genius loci merupakan konsep keunikan suatu tempat, yang terbentuk karena dialog antara lingkungan alam dengan lingkungan binaan. Genius loci kampung Areng di Lembang terbentuk karena munculnya fasilitas eduwisata astronomi di kampung ini. Objek studi kajian ini menelusuri genius loci Imah Noong sebagai tempat wisata bertema astronomi. Metode yang digunakan dalam kajian ini adalah metode deskriptif kualitatif dengan pendekatan place making. Genius Loci dari wisata astronomi Imah Noong dilihat dari image, character, space yang terbentuk di kawasan tersebut. Dari kajian tersebut, ditemukan bahwa genius loci Imahnoong terbangun karena adanya banyak aktivitas wisata yang terkait dengan aktivitas pendidikan, sosial, dan ekonomi. Perpaduan antara lingkungan alam pegunungan yang pas untuk aktivitas wisata astronomi yang dipadukan dengan aktivitas pendidikan, sosial, dan ekonomi menjadikan keunikan bagi kawasan Kampung Areng.
\end{abstract}

Kata kunci - genius loci, image, character, space, place, wisata, astronomi

\section{PENDAHULUAN}

Konsep Genius Loci, atau Kecerdasan Tempat, muncul untuk menjelaskan mengapa suatu tempat (place) bisa menjadi unik. Keunikan ini muncul karena ada perpaduan lingkungan alam dan lingkungan binaan manusia. Dalam praktiknya, Genius Loci muncul karena ada proses yang membentuk keunikan tempat tersebut.

Di Kampung Areng, sebuah kawasan perdesaaan di Lembang, Bandung, menjadi suatu tempat yang mempunyai keunikan karena adanya aktivitas eduwisata. Di desa ini, hadir seorang tokoh. yang kemudian mampu menggerakkan aneka aktivitas kreatif di desa tempatnya tinggal dan bekerja. Kreativitas ini kemudian banyak menarik keikutsertaan banyak orang sehingga terbangun suatu komunitas kreatif yang secara temporer yang menarik perhatian orang datang dan membangun aktivitas eduwasata di kawasan ini. Di sinilah, Kampung Areng dikenal karena keunikan akibat aktivitas eduwisata ini.

Kajian ini mencoba menelusuri genius loci yang terbentuk akibat adanya aktifitas baru di lokasi wisata Imah Noong di Desa Wangunsari Kecamatan Lembang Kabupaten Bandung. Di desa ini sudah tumbuh komunitas di bidang astronomi (peneropongan bendabenda langit). Keberadaan Observatorium Bosscha di dekat desa ini kawasan ini menjadi salah satu pemicu munculnya aktivitas eduwisata di Kampung Areng, karena fungsinya sebagai sarana penelitian membatasi kunjungan wisata umum di Observatorium Bosscha. Tulisan ini akan melihat bagaimana aktivitas eduwisata ini mampu memunculkan keunikan pada tempat yang tercipta (place-making) dalam kerangka Genius Loci. 
Merujuk pada pemikiran Norberg-Schultz [4], Genius Loci kampung Areng akan dijelajahi melalui pembacaan terhadap image, character, space yang terbentuk di kawasan tersebut. Dengan kajian ini, diharapkan bisa ditemukan kecerdasan lokal yang dibangun antara masyarakat pada lingkungan fisik yang mewadahi kegiatannya, dan maknanya bagi komunitas yang memanfaatkannya

\section{METODE}

Kajian ini merupakan hasil dari pengamatan terhadap genius loci dari eduwisata Astronomi di Kampung Areng, Lembang, yaitu Imah Noong. Genius loci terdiri dari dua kata yaitu terdiri dari dua kata, yaitu loci (dalam Bahasa latin disebut locus) yang berarti "tempat", dan genius, yang berarti "roh atau jiwa", sehingga Genius loci dalam hal ini dapat diartikan sebagai "jiwa tempat" (spirit of place). Norberg-Schulz [4] menyatakan bahwa sebuah tempat memiliki arti lebih karena memiliki 'roh/jiwa' yang tidak dapat dijelaskan secara analitis maupun metode ilmiah.

Menurut Norberg-Schultz [4], Genius Loci ditelusuri lewat image, character, space yang terbentuk di kawasan tersebut. Penelitian untuk mengungkap Genius Loci suatu tempat sebelumnya dilakukan oleh Ekomadyo [1] untuk Pasar Simpang Bandung dan Pasar Bintoro Demak, Ekomadyo [1] untuk Pasar Legi Surakarta dan Pasar Balubur Bandung, Putra dan Ekomadyo [5] untuk melihat warung kopi di Aceh, Siregar, dkk [7] untuk melihat kawasan bersejarah di Medan, dan Nasution, dkk [3] dalam mengkaji kawasan Kesawan di Medan.

Metode yang dipilih adalah metode diskriptif kualitatif yang dilakukan dengan teknik survey. Survey dilakukan adalah survey kepustakaan mengumpulkan data dengan mempelajari semua pustaka yang berkaitan dengan judul penelitian, baik yang langsung maupun tidak langsung, serta survey lapangan ke obyek studi dan mengadakan wawancara tidak tersetruktur.

\section{HASIL DAN DISKUSI}

\subsection{Deskripsi Kawasan Eduwisata Imah Noong di Kampung Areng}

Planetarium di kampung Eduwisata Areng No 31, Rt 02, Rw 12, desa Wangunsari, kecamatan Lembang, Kabupaten Bandung Barat. pendiri dari Imah Noong yaitu bapak Hendro Setyanto. Selain Kegiatan pengamatan benda langit, Imah Noong juga menawarkan kegiatan lain dengan memanfaatkan kearifan lokal setempat dan melibatkan petani serta peternak dalam Kegiatan eduwisata. Selain itu imah noong juga mengembangkan atau mendirikan sekolah untuk masyarakat sekitar Imah Noong.

\subsection{Fenomena Place-Making dan Genius Loci Imah \\ Noong}

Untuk menelusuri Genius Loci di suatu tempat, maka terlebih dulu dilihat bagaimana tempat tersebut terbentuk (place-making). Dengan konsep penciptaan tempat, maka pengunjung akan bisa mendapatkan suasana tertentu, membangun kaitan emosional, dan akhirnya mempelajari nilai-nilai yang terkandung budaya lokal kawasan tersebut.

Dalam perspektif kawasan eduwisata, konsep place dilihat sebagai ruang yang diciptakan agar makna dari suatu tempat bisa dikonsumsi oleh wisatawan. Karena sebagai kawasan eduwisata, maka perlu dilihat bagaimana pengetahuan astronomi bisa menjadi sarana untuk wisata Imah Noong di Kampung Areng.

Place akan ditelusuri dari relasi antara lingkugan binaan dengan aneka atraksi-atraksi wisata yang tersaji. Bagaimana makna tempat yang terbentuk di Imah Noong di Kampung Areng, penelusuran dilakukan dengan melihat image, space, character, hingga bisa dirumuskan Genius Loci-nya.

Image yang terbentuk untuk Imah Noong di Kampung Areng adalah sebagai tempat untuk melihat bintang atau observatorium. Image ini ditandai dengan banyaknya peralatan astronomi, yaitu Saung Noong yang berisi teleskop untuk meneropong bintang dan musholatorium, yang merupakan gabungan fungsi musola dan planetarium (diperlihatkan pada Gambar 1 dan Gambar 2). Dengan aktivitas meneropong bintang, terutama dilakukan oleh anak-anak dalam rangka belajar, maka image Imah Noong sebagai sarana eduwisata astronomi terbangun kuat.

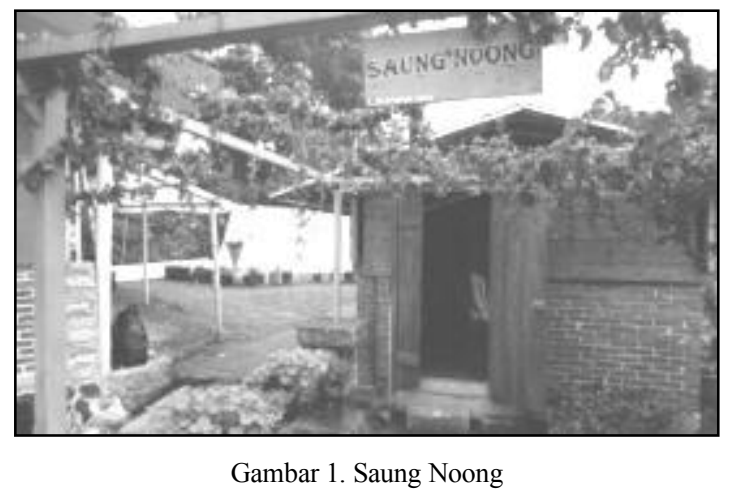




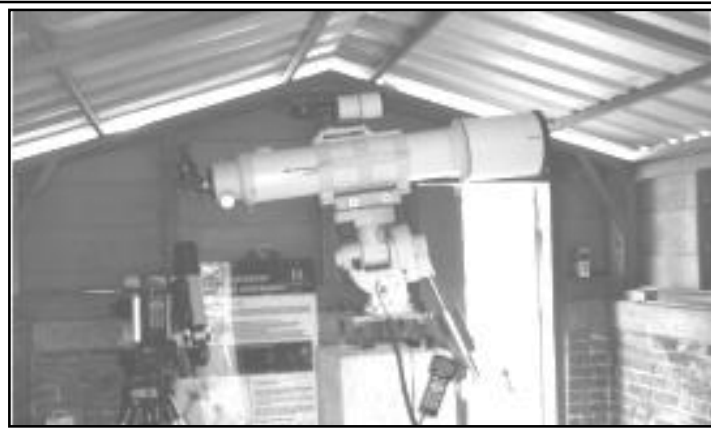

Gambar 2. Musholatorium di Imah Noong

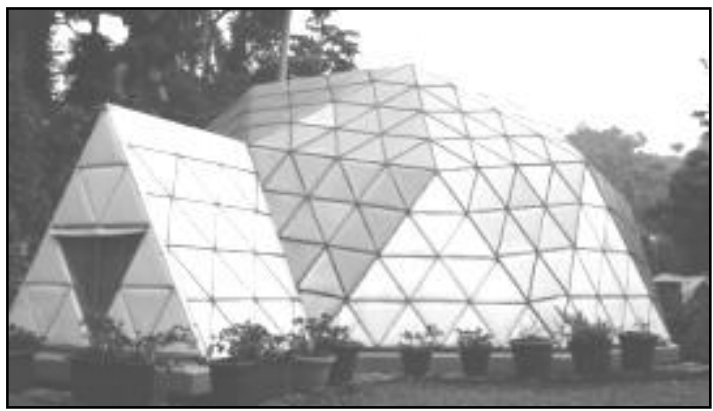

Gambar 3. Event Eduwisata Astronomi

Space pada lokasi kajian terbentuk dari aktivitas eduwisata yang ditawarkan oleh Imah Noong. Space tercipta karena relasi antara peralatan peneropongan bintang dengan aktivitas belajar dari anak-anak. Ruangruang tersebut terbentuk noong bareng gerhana bulan atau bulan purnama, pasar purnama, melihat dokumentasi atau film terkait astronomi, diskusi pakar terkait astronomi, ramadhan starcam dan lain sebagainya (diperlihatkan pada Gambar 2).

Untuk lebih memformalkan ruang belajar, dibuat sekolah Imah Noong. Awalnya sekolah ini khusus memberikan materi Astronomi bagi anak-anak dari luar Kampung Areng. Namun kemudian, yang memperluas aktivitas edukasi untuk warga sekitar, dibuat sekolah untuk warga sekitar, dalam bentuk Pendidikan Anak Usia Dini atau PAUD (diperlihatkan pada Gambar 5). Pelibatan warga sekitar terhadap kegiatan eduwisata akan mempengaruhi bagaimana ruang-ruang dibentuk agar Imahnoong berkarakter sebagai kawasan Eduwisata berbasis komunitas.

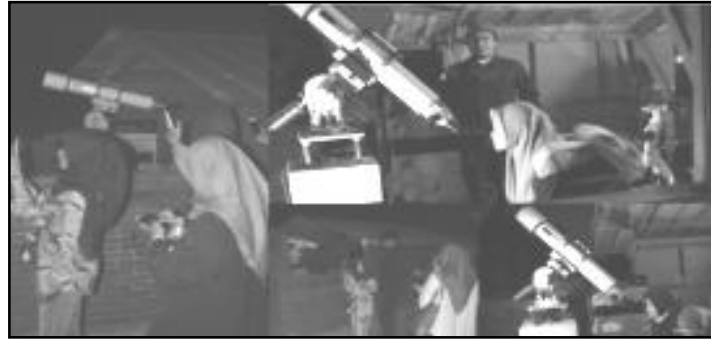

Gambar 4. Event Eduwisata bertema astronomi

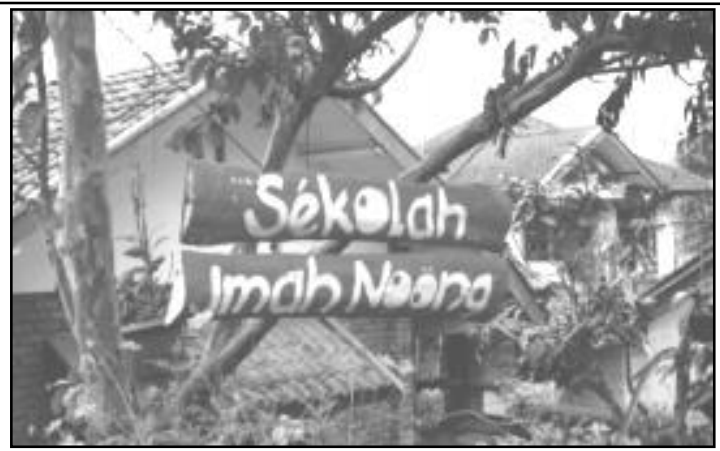

Gambar 5. Penanda Sekolah Imah Noong

Character khas yang membedakan Imah Noong dengan lokasi wisata astronomi lainnya adalah Imah Noong sebagai lokasi wisata observatorium arstronomi dan planetarium selalu mengadakan event terkait edukasi dan selalu melibatkan masyarakat sekitar untuk setiap event yang diselenggarakan. Di tempat ini banyak

Genius loci merupakan jiwa atau ruh suatu tempat. Ruh Imah Noong tokoh kreatif yang merupakan inisator atau pendiri dari Imah Noong yaitu bapak Hendro Setyanto. Beliau mendirikan Imah Noong tidak sematamata hanya untuk tempat wisata namun juga untuk tempat belajar tentang astronomi selain itu juga Imah Noong dapat bermanfaat bagi masyarakat sekitar. Genius Loci Imah Noong dalam peran untuk masyarakat sekitar adalah keberadaannya memberikan dampak sosial, ekonomi dan pendidikan bagi masyarakat sekitar.

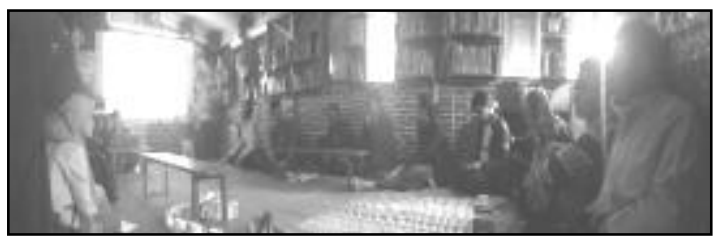

Gambar 6.a. Event Diskusi Pakar-Pakar Astronomi

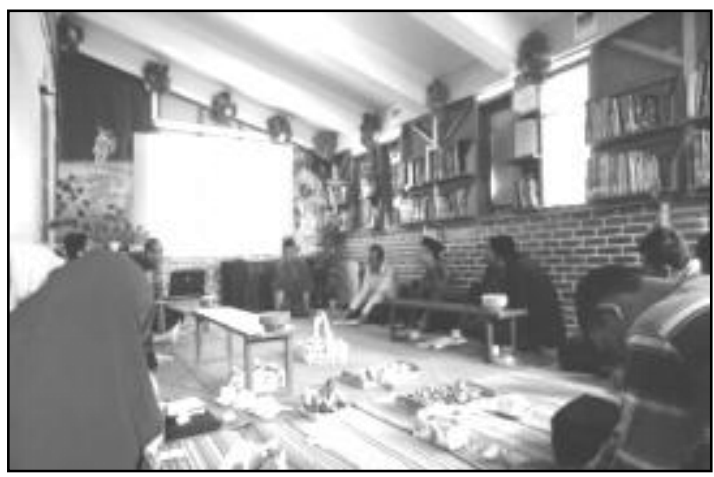

Gambar 6.b. Event Diskusi Pakar-Pakar Astronomi 


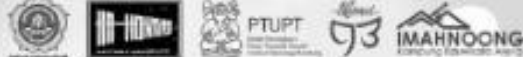

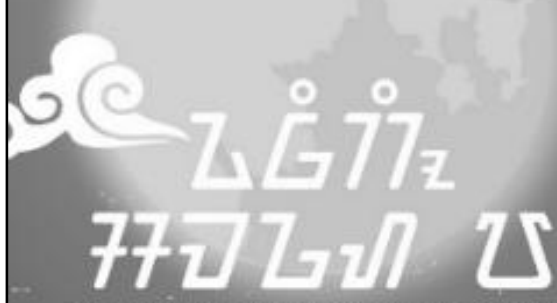

Ngawangkong Samagaha

$27-28$ Juli 2018

Pasar Purnama

18.00 s.d. 22.00. wibo

Gerhana Bulan Total

01:24s:d. $05: 19$ wibe

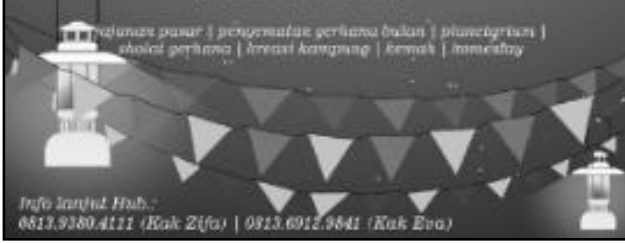

Gambar 7.a. Event Pasar Purnama

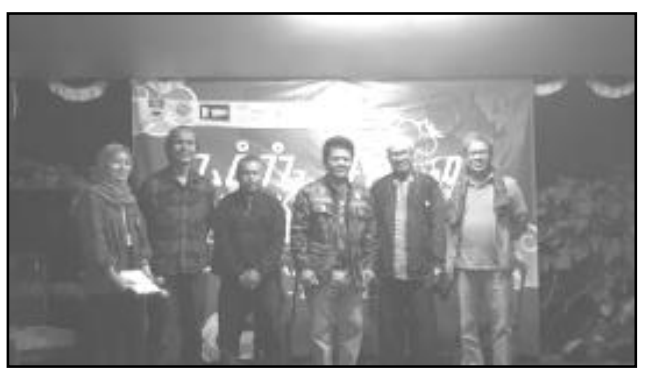

Gambar 7.b. Event Pasar Purnama

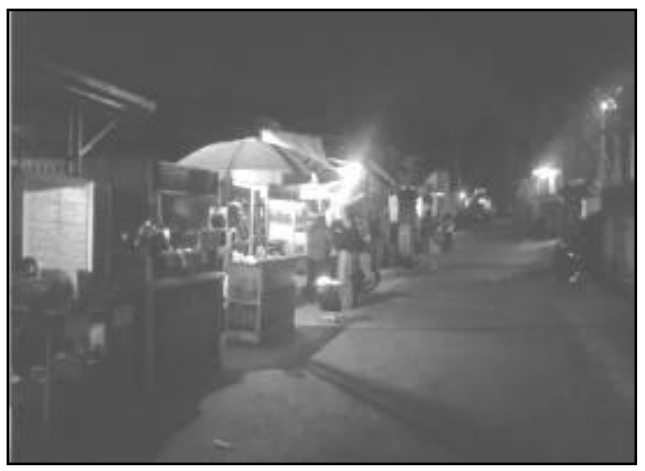

Gambar 7.c. Event Pasar Purnama

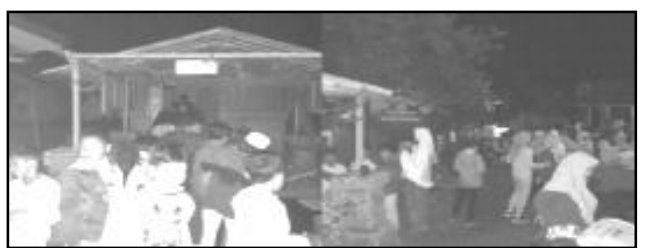

Gambar 7.d. Event Pasar Purnama

\section{KESIMPULAN}

Imah Noong merupakan observatorium arstronomi dan planetarium di kampung Eduwisata Areng Imah Noong merupakan genius loci kampung Areng. Genius loci atau ruh dari imah noong sendiri adalah pendiri Imah Noong. Genius loci imah noong dilihat dari image, space, character dapat memberikan dampak social, ekonomi, pendidikan untuk masyarakat sekitar.

\section{DAFTAR PUSTAKA}

[1] Ekomadyo, Agus, "Menelusuri genius Loci Pasar Tradisional sebagai Ruang Sosial Urban di Nusantara", Makalah Dipersentasikan dalam Seminar Arsitektur Nusantara, 2012.

[2] Ekomadyo, Agus S., Zahra, Atya., Najmi, Isan, "Public Market as Urban Social Nodes: an Architecture Phenomenology Approach", Makalah dipersentasikan pada Artepolis 4 International Coference on Creative and the Making of Place; Living Smart by Design. School of Architecture Planning and Policy Development, Proceedings vol 1, pp 169-180. Juli 2012.

[3] Nasution, A. D, Veronica, S., Adriansyah, W. A., Priatna, B. D., dkk (2019). Kajian Genius Loci dalam Uji Signifikansi Kawasan Kesawan Talenta Conference Series: Energy \& Engineering (EE) Volume 2 Issue 1 - 2019. Doi : 10.32734/ee.v2i1.386

[4] Norberg schultz, Christian. "Genius Loci: Towards a Phenomenology of Architecture". New York: Rizzoli. 1991.

[5] Project for Public Space. "Placemaking on Providence Waterfront”, PPS Inc. New York. 2009.

[6] Putra, R.A, dan Ekomadyo, A. S. Interpretasi Makna Pada Warung Kopi Aceh. Studi Kasus : Warung Kopi Solong di Banda Aceh. Jurnal Atrium: Jurnal Arsitektur Vol .1 No.1. ISSN 2442-7756, Universitas Kristen Duta Wacana Yogyakarta, Mei 2015

[7] Siregar, H.H., Natalivan, P., Ekomadyo, A.S. Cultural Assemblage As Genius Loci: Character Analysis Of Medan City Center District. International Conference of Architectural Education in Asia (Eduarchsia), Indonesian Islamic University, Yogyakarta, November 9, 2017, https://doi.org/10.1051/shsconf/20184104011

[8] Williams, D.R, "Leisure identities, globalization, and the politics of place". Journal of Leisure Research, 34,pp 351-367, 2002.

[9] Santri, T. , 2018 . Analisis Karakteristik Visual Arsitektur Pemukiman Nelayan. Jurnal Tiarsie, 15(2), 55-60. 